\title{
PREVALENCE OF ANAEMIA AND ITS ASSOCIATED FACTORS AMONGST PREGNANT WOMEN IN BHOPAL: A HOSPITAL BASED STUDY.
}

\section{Gynaecology}

\section{Dr. Archana Meravi}

\section{Dr. Juhi Agarwal*}

Senior Resident, Department Of Obstetrics \& Gynaecology, Gandhi Medical College, Bhopal, Madhya Pradesh.

Professor, Department Of Obstetrics \& Gynaecology, Gandhi Medical College, Bhopal, Madhya Pradesh. *Corresponding Author

\section{ABSTRACT}

BACKGROUND: Anemia during pregnancy is a global public health challenge facing in the world at present. It is estimated that around 2 billion people, ( $30 \%$ of world population) are affected, with the majority coming from the developing world.

AIM: This study was conducted to assess the prevalence of anaemia and its associated morbidity amongst pregnant females.

MATERIAL AND METHOD: The present study was a hospital- based observational study that was conducted in Department of Obstetrics and Gynaecology, Sultania Zanana Hospital ,Gandhi Medical College, Bhopal ,Madhya Pradesh, India and included all the pregnant women in third trimester of pregnancy with haemoglobin levels less than 7 who were admitted between January 2016 to December 2016. Data were analysed using SPSS v20.

RESULT: A total of five hundred cases were enrolled for the study.Most were 21-35 year old (74.2\%) followed by less than 20 year old subjects $(18.8 \%)$. Anaemia was more prevalent among rural population as compared to urban population.It was found to be prevalent in lower socioeconomic status. Of all, $43 \%$ were secondary school graduates whereas $24 \%$ were illiterates. Sixty nine percent study population were multigravida with $37.6 \%$ having pregnancy within one-year of the previous.

CONCLUSION: The main risk factors were found to be the education level, gravidity and inter-pregnancy levels. Residence and type of diet were also found to be significant. There is need for educational awareness programmes to be conducted amongst pregnant women to improve their knowledge regarding causes and prevention of anaemia for a better antenatal and perinatal outcome.

\section{KEYWORDS}

Anaemia, Pregnancy, Multi-gravida, Morbidity

\section{INTRODUCTION}

Iron deficiency anaemia is ranked as the fifteenth leading cause of disability-adjusted life years (DALYs) by the WHO in 2012.[1]WHO data estimate that iron deficiency anaemia in children and adults results in 19.7 million DALYs, or 1.3\% of global total DALYs [2].According to a WHO review of nationally representative surveys from 1993 to 2005 , anaemia affects approximately $42 \%$ of pregnant women worldwide (52 and $23 \%$ in developing and developed countries, respectively) $[3,4]$. India is one of the countries with very high prevalence of anaemia in the world. Almost $58 \%$ of pregnant women in India are anaemic and it is estimated that anaemia is the underlying cause for $20-40 \%$ of maternal deaths in India. India contributes to about $80 \%$ of the maternal death due to anaemia in South Asia. Anaemia reduces women's energy and capacity for work and can therefore threatened household food security and income. Also severe anaemia in pregnancy impairs oxygen delivery to foetus and interferes with normal intrauterine growth, resulting in intrauterine growth retardation, still birth, LBW and neonatal deaths. Therefore anaemia is a major contributor to poor pregnancy and birth outcomes in developing countries as it predisposes to premature delivery, increased perinatal mortality and increased risk of death during delivery and postpartum.Keeping this view in mind the study was carried out with the objectives to assess the magnitude and risk factors for anaemia among urban pregnant woman in tertiary care centre of central India.

\section{MATERIALAND METHOD}

The present study is a Hospital- based Observational study that was conducted in Department of Obstetrics and Gynaecology, Sultania Zanana Hospital ,Gandhi Medical College, Bhopal ,Madhya Pradesh,India.All the pregnant women at third trimester who was admitted at Sultania Zanana Hospital, Bhopal from January 2016 to December 2016 having haemoglobin level $<7 \mathrm{gm} / \mathrm{dl}$ were included in the study.

Sample size was drawn using formula $4 \mathrm{pq} / \mathrm{L} 2$ where $\mathrm{p}=$ prevalence of anaemia, $q=1-p$ and $\mathrm{L}=$ level of error. According to this , the sample size was calculated to be 500 .

\section{INCLUSION CRITERIA}

(a)All pregnant women at third trimester admitted at our institute, $\mathrm{SZH}$ (b)Antenatal mothers who are willing to participate in the study. (c)Who are present at the time of data collection. (d)Who can underst and and communicate in Hindi

\section{EXCLUSION CRITERIA}

All admitted cases of anaemia came with antepartum haemorrhage (APH) and shock, who were subjected to blood transfusion in last three months and with history of some diseases that may affect the result such as ; liver diseases, renal diseases, diabetes mellitus were excluded.

\section{DATA COLLECTIONAND STATISTICALANALYSIS}

Data was collected using instructed writing questionnaire by interviewing: regarding the patient name, age, residence, antenatal booking status, gestational age, education, socioeconomic status, number of gravidity, blood groups, previous blood transfusion, history of diseases supportive supplements and tea intake, maternal follow up, inter pregnancy interval. Gestational age was assessed from the date of the last menstrual period and only term pregnancies were included in the study. Data were analysed by SPSS v 20. Comparisons among clinical variables were performed with Person Chi-square test. All tests were 2 -tailed and the statistical significance was set as $\mathrm{P}<0.05$.

\section{RESULTS}

500 anaemic pregnant women were selected for the study to identify the risk factors that contribute to the presence and severity of anaemia and to assess maternal morbidity and mortality. Anaemia was more prevalent amongst 21-35 year old study subjects. Out of 500 anaemic pregnant women, $\operatorname{most}(74.2 \%)$ were $21-35$ year old followed by age less than 20 year old subject( $18.8 \%)$. Only $35(7.0 \%)$ were more than 35 year old. Of all the patients, $121(24.2 \%)$ were illiterate and most of $215(43.0 \%)$ were below 10th standard. 161(32.2\%) were high school graduates and only $03(0.65 \%)$ were college graduates. Anaemia was more prevalent among low income class. Out of 500 anaemic pregnant women, $327(65.4 \%)$ were of low income class. $149(29.8 \%)$ were of middle income class and 24(4.8\%) were of high income class. \{ pValue $0.33(\mathrm{~S})\}$ Anaemia was more prevalent among rural population as compare to urban population. Out of 500 study subjects, $314(62.8 \%)$ were from rural locality and $186(37.2 \%)$ from urban location. \{p-Value 0.001(HS)\}Out of 500 study subjects, most of $325(65.0 \%)$ were from Muslim community and 170(34.0\%) were Hindu. Sikh and Christian were very less in number.Anaemia were seen more prevalent among women from joint family as compare to nuclear family. Out of 500 study subjects, 301(60.2\%) were from joint family and $199(39.8 \%)$ were from nuclear family. Most of the patients in the study,343(68.6\%) were multigravida, $101(20.2 \%)$ were grandmulti and 56(11.2\%) were primigravida. Regarding the eating habits the study showed that out of 500 study subjects, most of 377(75.4\%) 
were non vegetarian and $123(24.6 \%)$ were vegetarian and among $124(24.8 \%)$ PICA was present. Most of the patients, $167(37.6 \%)$ were having 1 year inter pregnancy interval, $187(42.11 \%)$ were having 2-3 year interval in pregnancy and $90(20.2 \%)$ had more than 4 year interval in pregnancy. $\{$ p- Value $0.001(\mathrm{HS})\}$ Out of 500 anaemic pregnant women, 226(45.2\%) were having normocytic hypo-chromic anaemia , $218(43.6 \%)$ had microcytic hypo-chromic anaemia and 56(11.2\%) had macrocytic hypo-chromic anaemia. Level of Haemoglobin among anaemic pregnant women as per ICMR Classification shows that out of 500 patients, most of $203(40.6 \%)$ were having 5-6.9 gm/dl haemoglobin, 144(28.8\%) had only less than $4 \mathrm{gm} / \mathrm{dl}$ haemoglobin and $153(30.6 \%)$ had $7 \mathrm{gm} / \mathrm{dl}$ haemoglobin.

Table-1:Predictors of anaemia during pregnancy (Logistic Regression Analysis)

\begin{tabular}{|l|l|l|l|l|l|}
\hline Variables & & $\begin{array}{l}\text { Odds } \\
\text { Ratio }\end{array}$ & $\begin{array}{l}\text { Confidence } \\
\text { Interval(95\%) }\end{array}$ & B Coefficient & p-Value \\
\hline Income & High Class & 1 & - & 0.456 & $0.033(\mathrm{~S})$ \\
\cline { 2 - 5 } & Low Class & 1.572 & $0.988-2.456$ & & \\
\hline \multirow{2}{*}{ Locality } & Urban & 1 & - & 0.987 & $0.001(\mathrm{HS})$ \\
\cline { 2 - 4 } & Rural & 2.371 & $1.654-3.098$ & & \\
\hline \multirow{2}{*}{$\begin{array}{l}\text { No. of } \\
\text { Children }\end{array}$} & Primigravida & 1 & - & 1.873 & $0.001(\mathrm{HS})$ \\
\cline { 2 - 4 } Diet & Multigravida & 2.987 & $1.567-3.987$ & & \\
\hline & $\begin{array}{l}\text { Non- } \\
\text { Vegetarian }\end{array}$ & 1 & - & 1.998 & $0.045(\mathrm{~S})$ \\
\cline { 2 - 4 } & Vegetarian & 2.121 & $1.876-4.098$ & & \\
\hline PICA & PICA Absent & 1 & - & 1.032 & $0.001(\mathrm{HS})$ \\
\cline { 2 - 4 } & $\begin{array}{l}\text { PICA } \\
\text { Present }\end{array}$ & 2.167 & $1.540-3.145$ & & \\
\hline $\begin{array}{l}\text { Inter } \\
\text { Pregnancy } \\
\text { Interval }\end{array}$ & $>2$ Year & 1 & - & 1.765 & $0.006(\mathrm{~S})$ \\
\hline
\end{tabular}

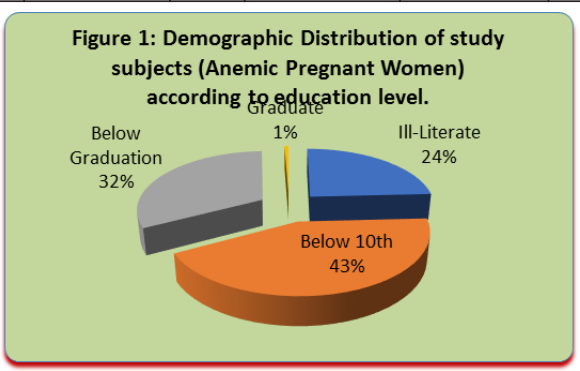

Table-2:SEVERE MATERNAL MORBIDITY ( ICD -9, 10) IN $\operatorname{ANEMIC~WOMEN}(\mathbf{n}=\mathbf{5 0 0})$

\begin{tabular}{|c|c|c|c|c|c|}
\hline \multirow[t]{2}{*}{ S. NO } & \multirow{2}{*}{$\begin{array}{l}\text { MATERNAL } \\
\text { MORBIDITY }\end{array}$} & \multirow[t]{2}{*}{ TOTAL } & \multicolumn{3}{|c|}{$\mathrm{Hb}$} \\
\hline & & & $7 \mathrm{gm} / \mathrm{dl}$ & $5-6.9 \mathrm{gm} / \mathrm{dl}$ & $<4 \mathrm{gm} / \mathrm{dl}$ \\
\hline 1. & Acute renal failure & 11 & 02 & 04 & 05 \\
\hline 2. & Liver failure & 0 & 0 & 0 & 0 \\
\hline 3. & Respiratory failure & 0 & 0 & 0 & 0 \\
\hline 4. & Obstetric shock & 0 & 0 & 0 & 0 \\
\hline 5. & $\begin{array}{l}\text { Cerebrovascular } \\
\text { accident }\end{array}$ & 10 & 03 & 05 & 02 \\
\hline 6. & \begin{tabular}{|l|}
$\begin{array}{l}\text { Pulmonary } \\
\text { embolism }\end{array}$ \\
\end{tabular} & 32 & 09 & 17 & 06 \\
\hline 7. & $\begin{array}{l}\begin{array}{l}\text { Amniotic fluid } \\
\text { embolism }\end{array} \\
\end{array}$ & 0 & 0 & 0 & 0 \\
\hline 8. & Eclampsia & 59 & 36 & 17 & 06 \\
\hline 9. & Septicemia & 63 & 22 & 28 & 13 \\
\hline 10. & $\begin{array}{l}\text { Complication of } \\
\text { Anesthesia }\end{array}$ & 0 & 0 & 0 & 0 \\
\hline 11. & \begin{tabular}{|l|} 
Procedure based \\
(Cardiac procedure)
\end{tabular} & 12 & 07 & 04 & 0 \\
\hline 12. & $\begin{array}{l}\text { Mechanical } \\
\text { ventilation }\end{array}$ & 21 & 05 & 09 & 07 \\
\hline 13. & $\begin{array}{l}\text { Transfusion } \\
\text { reaction }\end{array}$ & 08 & 04 & 03 & 01 \\
\hline & hi Square Value & & & 27.6 & \\
\hline & p- Value & & & $016(\mathrm{~S})$ & \\
\hline
\end{tabular}

\section{DISCUSSION}

Anaemia and iron deficiency are common during pregnancy $[5,6]$. A small decrease in haemoglobin $(\mathrm{Hb})$ is a normal physiological consequence of the increase in blood plasma volume during pregnancy. Normally, after an initial increase (due to the cessation of menstruation), $\mathrm{Hb}$ levels decrease by around $20 \mathrm{~g} / \mathrm{l}$ and reach their lowest level during the second trimester, returning to pre-pregnancy levels as the pregnancy advances toward term $[5,7]$. The increase in iron requirements during pregnancy results from increased total blood cell volume, the requirements of the foetus and placenta and, during labor, blood loss [6,7]

In the case of iron deficiency anaemia during pregnancy, there are several possible risks to the mother, including increased fatigue, shortterm memory loss, decreased attention span and decreased performance at work, increased pressure on the cardiovascular system due to insufficient $\mathrm{Hb}$ and low blood oxygen saturation levels, lower resistance to infections and a reduced tolerance to significant blood loss and to surgical intervention during labor $[8,9]$. The presumed risks of iron deficiency for the foetus relate to the fact that low iron levels increase the risk of reduced $\mathrm{Hb}$ levels, and therefore oxygen, to the uterus, placenta and the foetus during development [9]. Moreover, iron-deficient neonates have been shown to have a statistically significant increment in both cognitive and behavioural abnormalities up to 10 years after iron repletion. Iron deficiency anaemia, even if mild to moderate, can be associated with unfavourable obstetric outcomes, notably, premature birth, low birth weight and foetal death $[5,6,9]$

Anaemia were more prevalent among 21-35 year old study subjects.It was observed that anaemia was more prevalent among rural population as compared to urban population and amongst the patients of lower socioeconomic status.It was also found that anaemia was more prevalent among women from joint family as compared to nuclear family. The present study showed that severe anaemia was more prevalent among rural population $62.8 \%$ as compare to urban population $37.2 \%$ found to be significantly associated with anaemia (p-Value 0.001).Studies of NirmalaDevi Dr.B et al (2007), F Asrai et al, Mishu Mangla \& Deepak Singla et al(2014), showed that prevalence of anaemia was significantly associated with rural residence.[10] Data from NFHS 2 showed that the prevalence of anaemia in pregnant women was 49.7 per cent and that there was no difference in the prevalence of anaemia between non-pregnant and pregnant women.These findings were initially interpreted as steep fall in the prevalence of anaemia in pregnancy due to successful implementation of NACP. At national level, NFHS3 reported a 10 per cent increase in the prevalence of anaemia from NFHS 2 (49.7 to 58.3\%). [11] Between NFHS 3 and 4, there was a reduction in the prevalence of anaemia from 58.3 to 50.3 per cent. The prevalence of anaemia in NFHS 4 was comparable to the prevalence of anaemia in NFHS 2 suggesting that there had not been any decline in the prevalence of anaemia in pregnancy over the last two decades. The prevalence of anaemia was higher in Assam, Odisha and Jharkhand as compared to Kerala, Punjab, Himachal and Delhi. No substantial or consistent decline was observed in prevalence of anaemia in pregnant women between NFHS 2,3 and 4 in any of the States.[12-15]

These observations differs from the results of other countries as it was observed that the overall prevalence was almost comparable to the results of studies conducted in Republic of Korea (30.2\%), South Africa (19.7\%),rural areas of Southern Ethiopia (29\%) and Azezo $(21.6 \%) \cdot[14-20]$

In the present study we found that among all severely anaemic pregnant women $45.2 \%$ were having normocytic hypochromic ana emia , $43.6 \%$ had microcytic hypo-chromic anaemia and $11.2 \%$ had macrocytic hypo-chromic anaemia. Rawat K et al (2016),30 showed in his study that microcytic hypo-chromic anaemia 51\% was most prevalent, other morphological types reported as normocytic normochromic anaemia, dimorphic anaemia and macrocytic anaemia as $32 \%, 13 \%$ and $4 \%$ respectively.Similar findings were reported in the study by Sewa reported prevalence was $53.6 \%$.

Karaoglu et al(2010),49 in his study found that $56.5 \%$ pregnant women had normocytic - normochromic anaemia and $38.1 \%$ had microcytic -hypo chromic anaemia.[18-20]

The present study revealed that, out of 500 cases, $40.6 \%$ women had haemoglobin level between $5-6.9 \mathrm{gm} / \mathrm{dl}$ followed by $30.6 \%$ had haemoglobin $7 \mathrm{gm} / \mathrm{dl}$ only $28.8 \%$ had haemoglobin below $4 \mathrm{gm} / \mathrm{dl}$. ( ICMR classification).Rai Neeraj and Rai Pushpa et al (2014), in their 
study in Bundelkhand Region of Madhya pradesh showed that 74.7\% pregnant women were anaemic of which $7.3 \%$ had severe anaemia.[21] Nirmala Devi Dr.B, Lahari Dr. N et al (2007), reported in her study that $86.02 \%$ women with Haemoglobin $5-7 \mathrm{gm} / \mathrm{dl}$ followed by $13.08 \%$ women had haemoglobin less than $5 \mathrm{gm} / \mathrm{dl}$.[22] Ghosh S et $\mathrm{al}(2005)$, study was conducted in Eastern Indian states reported that $1.6 \%$ were severely anaemic $(<7.0 \mathrm{gm} / \mathrm{dl})$. Bentley ME and Griffiths PL et al (2003),in his study found that $2.2 \%$ pregnant women were severely anaemic.[23,24] Another report from India in 2010 also showed that the majority $(50.9 \%)$ had moderate anaemia, with mild type of anaemia accounting for $30.17 \%$ and severe anaemia for $18.9 \%$, respectively.[25]

In this study, no association between anaemia and the number of children was observed

This finding is supported by the findings of previous reports in Eastern Sudan, Nigeria, and Zaire and is contrary to a report from Tanzania. [26-29]

The incidence of anaemia during pregnancy is expected to be higher as the number of pregnancies increases because of the repeated drain on the iron reserves. In fact, multiparty, especially when the pregnancies have occurred in a rapid sequence, is traditionally regarded as a cause of anaemia in pregnancy. However, the present study showed no consistent relationship between increasing number of children and the incidence of anaemia. Possibly, the experience gained from the first pregnancy followed by increased awareness and good dietary practices, as well as increased interaction with other pregnant women at the antenatal clinic, might counterbalance its effect. This study also did not observe any relationship between prevalence of anaemia and increasing gestational age, suggesting that all pregnant women were susceptible to anaemia throughout the gestational period. In order to avoid anaemia during pregnancy, receiving early antenatal care would serve as an important preventive measure. The same result was observed in a study conducted in India and Gondar. [30-32]

The present study revealed that anaemia was significantly associated with co -morbidities $25.4 \%$ women had pre- eclampsia $15.2 \%$ had eclampsia, $7.6 \%$ had jaundice ,3.6\% had heart disease and $4.8 \%$ had intercurrent infection.

We found that out of 500 anaemic pregnant women 216 women had severe maternal morbidity this was found to be significant ( $p$-Value 0.016) , 59 women had Eclampsia in their ante natal period, septicaemia was found in 63 women, 32 had pulmonary embolism, 12 women had surgical procedure for cardiac disease, acute renal failure (ARF) were found to be in 11 subjects, 21 subjects had need of mechanical ventilation and 08 women had transfusion reaction.

In our study maternal morbidity among anaemic pregnant women(ICD-10) were found to be significant (p-Value 0.036) in puerperal period, among 500 study subjects 41 women had Puerperal pyrexia, 32 women had puerperal sepsis, in 19 women sub involution was found , 19 women had episiotomy gaping and abdominal wound gap was found in 03 women.Similar results were observed by other studies conducted in the country suggesting that iron deficiency significantly increases the morbidity in females.[27-31]

\section{CONCLUSION}

Iron deficiency during pregnancy can be prevented or controlled by counselling individuals and families about sound iron nutrition and iron supplementation during pregnancy, by screening persons on the basis of their risk for iron deficiency and by treating and monitoring individuals with presumed iron deficiency. This may help to reduce the manifestations of iron deficiency and, consequently, improve public health. There is a need to intensify IEC activities to promote early antenatal care, dietary modification and utilisation of family planning services specially in under privileged population of the region.

\section{REFERENCES}

Guidelines for control of iron deficiency anaemia: national iron + initiative. Adolescentdivision ministry of health and family welfare, government of India. New Delhi.2013:512.

2. National nutrition monitoring bureau. Prevalence of micronutrients deficiencies. Technical report no.22. National institute of nutrition, Indian Council of Medical Research. Hyderabad. 2003:18-25.

3. de Benoist B, McLean E, Egli I, Cogswell M. Worldwide Prevalence Of Anaemia 1993-2005: Who Global Database On Anaemia. WHO, Geneva, Switzerland (2008)

4. Sanghvi TG, Harvey PW, Wainwright E. Maternal iron-folic acid supplementation programs: evidence of impact and implementation. Food Nutr. Bull. 31(Suppl. 2),
S100-S107 (2010).

Cao C, O’Brien KO. Pregnancy and iron homeostasis: an update. Nutr. Rev. 71(1), 35-51(2013).

6. Burke RM, Leon JS, Suchdev PS. Identification, prevention and treatment of iron deficiency during the first 1000 days. Nutrients 6(10), 4093-4114 (2014)

7. Scholl TO. Iron status during pregnancy: setting the stage for mother and infant. Am. J. Clin. Nutr. 81(5), S1218-S1222(2005)

8. Hercberg S, Preziosi P, Galan P. Iron deficiency in Europe. Public Health Nutr. 4(2B), $537-545(2001)$

9. Zimmermann MB, Hurrell RF. Nutritional iron deficiency. Lancet 370(9586), 511-520 (2007).

10. District Level Household Survey on Reproductive and Child Health, India 2002-2004 http://www.rchiips.org/pdf/rch2/ National- Nutritional- Report-RCH-II. pdf . Accessed on 16 may 2015.

11. International Institute of Population Sciences (IIPS) National Family Health Survey (NFHS) 3. [accessed on September 23, 2016]. Available from: http:// www. rchiips. org nfhs/nfhs 3. shtml

12. International Institute of Population Sciences (IIPS). National Family Health Survey (NFHS) 2. [accessed on September 23, 2016]. Available from: http:// www.r chiips. org/ nfhs/nfhs2.shtml.

13. International Institute of Population Sciences (IIPS) National Family Health Survey (NFHS) 3. [accessed on September 23, 2016]. Available from: http://www. rchiips. org/ nfhs/nfhs3.shtml.

14. International Institute of Population Sciences (IIPS) National Family Health Survey (NFHS) 4 Fact Sheets. [accessed on May 22, 2017].Availablefrom:htt p://w ww. rchii ps. $\mathrm{org} / \mathrm{nfhs} /$ factsheet_NFHS-4.shtml.

15. Kalaivani K, Ramachandran P. Combating triple burden of malnutrition: World health assembly targets for 2025. Bull Nutr Found India. 2017;38:1-8

16. Van Bogart LJ. Anaemia and pregnancy outcomes in a South African rural population. J Obstet Gynecol. 2006;26 (7):617-619.

17. Mart i-Carvajal A, Peña-Martí G, Comunian G, Muñoz S. Prevalence of anaemia durin pregnancy: results of Valencia (Venezuela) anaemia during pregnancy study. Arch Latinoam Nutr. 2002;52(1):5-11

18. Jamal HA, Rebecca PS. Iron deficiency anaemia is not a rare problem among women of reproductive ages in Ethiopia. BMC Blood Disord. 2009;9:7.

19. Becerra C, Gonzales GF, Villena A, de la Cruz D, Flori A. Prevalence of anaemia in pregnant women, Pucallpa Regional Hospital, Peru. Rev Panam Salud Publica. 1998;3(5):285-292.

20. Alem M, Enawgaw B, Gelaw A, Kena T, Seid M, Olkeba Y. Prevalence of anaemia an associated risk factors among pregnant women attending antenatal care in Azezo Health Center Gondar town, Northwest Ethiopia. J Interdiscipl Histopathol. 2013;1 (3): $137-144$

21. Neeraj Rai, Sunil Nandeshwar and Pushpa Rai:A study on magnitude of anaemia an its socio-demographic correlates among pregnant women in Sagar city of Bundelkhand its socio-demographic correlates among pregnant women in Sagar city of Bundelkhand 28132.DOI:http://dx.doi.org/10.18203/2394-6040.ijcmph20151511

22. NirmalaDevi Dr.B, Varalaxmi Dr. B, Jyothirmayi Dr.T, Lahari Dr. N (2007):Maternal outcome in pregnancy with severe anemia: Prospective study in a tertiary care hospital in Andhra Pradesh.IOSRJournal of Dental \& Medical Science (IOSR-JDMS) eISSN:2279-0853,P-ISSN:2279-0861.Volume14, Issue 4 Ver.IX(Apr.2015),PP06-10 www.iosrjournals.org.

23. Saswata Ghosh(2009): Exploring Socioeconomic vulnerability of anemia among women in Eastern Indian States. Volume 41, Issue 6 November 2009, pp. 763-787 https://doi.org/10.1017/S0021932009990149 Published online: 17 July 2009

24. Bentley ME1, Griffiths PL. The burden of anemia among women in India. Eur J Clin Nutr. 2003 Jan;57(1):52-60. PMID:12548297,DOI:10.1038/sj.ejcn.1601504

25. Vijaynath, Jitendra, Ramesh P, Abhishek P. Prevalence of anaemia in pregnancy. Indian J Appl Basic Med Sci. 2010;12:23-35

26. Adam I, Khamis AH, Elbashir MI. Prevalence and risk factors for anaemia in pregnan women of Eastern Sudan. Trans R Soc Trop Med Hyg. 2005;99:739-743.

27. Iloabachie GC, Meniru GI. The increasing incidence of anaemia in pregnancy in Nigeria. Orient J Med. 1990;2:194-197.

28. Jackson DJ, Klee EB, Green SD, Mokili JL, Elton RA, Cutting WA. Severe anaemia in pregnancy: a problem of primigravidae in rural Zaire. Trans R Soc Trop Med Hyg. 1991;85:829.

29. Hinderaker SG, Olsen BE, Bergsjo P, Lie RT, Gasheka P, Kvåle G. Anemia in pregnancy in the highlands of Tanzania. Acta Obstet Gynecol. 2001;80:18-26.

30. Levy A, Fraser D, Katz M, Mazor M, Sheiner E. Maternal anaemia during pregnancy is an independent risk factor for low birth weight and preterm delivery. Eur J Obste Gynecol Reprod Biol. 2005;122:182-186.

31. Mulgeta M, Zelalem A, Meseret A, Bamlaku E. Prevalence and predictors of materna anaemia during pregnancy in Gondar, north west Ethiopia. Hindawi Publish Corp. 2013:2014:2-3

32. Alem M, Enawgaw B, Gelaw A, Kena T, Seid M, Olkeba Y. Prevalence of anaemia and associated risk factors among pregnant women attending antenatal care in Azezo Health Center Gondar town, Northwest Ethiopia. J Interdiscipl Histopathol. 2013;1(3):137-144. 